Citation: W. Habib, J. Khalil, A. Mincuzzi, C. Saab, E. Gerges, H.C. Tsouvalakis, A. Ippolito, S.M. Sanzani (2021) Fungal pathogens associated with harvested table grapes in Lebanon, and characterization of the mycotoxigenic genera. Phytopathologia Mediterranea 60(3): 427-439. doi: 10.36253/ phyto-12946

Accepted: September 8, 2021

Published: November 15, 2021

Copyright: @ 2021 W. Habib, J. Khalil, A. Mincuzzi, C. Saab, E. Gerges, H.C. Tsouvalakis, A. Ippolito, S.M. Sanzani. This is an open access, peer-reviewed article published by Firenze University Press (http://www.fupress.com/pm) and distributed under the terms of the Creative Commons Attribution License, which permits unrestricted use, distribution, and reproduction in any medium, provided the original author and source are credited.

Data Availability Statement: All relevant data are within the paper and its Supporting Information files.

Competing Interests: The Author(s) declare(s) no conflict of interest.

Editor: Antonio Moretti, National Research Council, (CNR), Bari, Italy.
Research Papers

\section{Fungal pathogens associated with harvested table grapes in Lebanon, and characterization of the mycotoxigenic genera}

\author{
Wassim HABIB ${ }^{1}$, Jack KHALIL ${ }^{2, \S}$, Annamaria MINCUZZI ${ }^{3, \S}$, Carine \\ SAAB $^{1}$, Elvis GERGES ${ }^{1}$, Hala Chahine TSOUVALAKIS ${ }^{4}$, Antonio \\ IPPOLITO $^{3}$, SimONA MARIANNA SANZANI ${ }^{2, *}$ \\ ${ }^{1}$ Laboratory of Mycology, Department of Plant Protection, Lebanese Agricultural \\ Research Institute, Fanar, Lebanon \\ ${ }^{2}$ CIHEAM Bari, Via Ceglie 9, 70010 Valenzano (Bari), Italy \\ ${ }^{3}$ Department of Soil, Plant and Food Sciences, University of Bari Aldo Moro, Via Amen- \\ dola 165/A, 70126 Bari, Italy \\ ${ }^{4}$ Department of Plant Production, Faculty of Agricultural and Veterinary Sciences, Leba- \\ nese University, Dekwaneh, Lebanon \\ ${ }^{\S}$ Authors equally contributed to the research \\ * Corresponding author. E-mail: sanzani@iamb.it
}

Summary. Table grapes are exposed to fungal infections before and after harvest. In particular, Aspergillus, Penicillium, and Alternaria can cause decays and contamination by mycotoxins. The main fungi affecting Lebanese table grapes after harvest were assessed as epiphytic populations, latent infections, and rots. Effects of storage with and without $\mathrm{SO}_{2}$ generating pads were also evaluated. Representative isolates of toxigenic genera were characterised, and their genetic potential to produce ochratoxin $\mathrm{A}$, fumonisins, and patulin was established. The epiphytic populations mainly included wound pathogens (Aspergillus spp. and Penicillium spp.), while latent infections and rots were mostly caused by Botrytis spp. The use of $\mathrm{SO}_{2}$ generating pads reduced the epiphytic populations and rots, but was less effective against latent infections. Characterization of Aspergillus, Penicillium, and Alternaria isolates showed that A. tubingensis, P. glabrum, and A. alternata were the most common species. Strains of A. welwitschiae and $P$. expansum were also found to be genetically able to produce, respectively, ochratoxin A plus fumonisins and patulin. These data demonstrate the need for effective measures to prevent postharvest losses caused by toxigenic fungi.

Keywords. Postharvest, Aspergillus, Penicillium, Alternaria, mycotoxins, sulphur dioxide.

\section{INTRODUCTION}

Table grapes are among the most important fruit crops in Lebanon due to the favourable Mediterranean climatic conditions and long cultivation tradition. Table grapes are grown on 7,030 ha, with annual production of 62,014 $\mathrm{t}$ (FAOSTAT, 2019). Plantations for commercial production have long been made with the local cultivars Tfeifihi, Beitamouni, Maghdouchi, and Obeidi. 
Recently, however, commercial cultivars have been introduced from Europe and the United States (Chalak et al., 2016). Thirty-eight packinghouses and storage facilities exist in Lebanon, of which 22 process table grapes (Lebanese Chamber of Commerce, 2019). Most of these facilities are in the Bekaa region in Eastern Lebanon, where most table grape production occurs. The most common pre-cooling method, present in almost all these facilities, is the room cooling, where pre-cooling and storage are carried out in the same room at appropriate temperatures.

Grapes are susceptible to many fungal diseases in the field and during storage. Postharvest diseases, in favourable conditions and particularly in developing countries, can cause losses in total production of up to 55\% (Sanzani et al., 2016a). The most destructive postharvest disease of table grapes is grey mould caused by Botrytis spp. Infections often take place in the field, and the fungi remain latent until ripening (Sanzani et al., 2012). Other diseases can occur during storage, including blue mould caused by Penicillium spp., some of which can grow even in refrigerated conditions (Sanzani et al., 2013). The predominant Penicillium species isolated from grapes differ between vineyards and years, but the most common ones are $P$. brevicompactum, $P$. citrinum, $P$. glabrum, and $P$. expansum (Rousseaux et al., 2014). Other diseases are more recurrent in presence of warm temperatures (e.g., during transportation and marketing). These include rots caused by Aspergillus spp. (Droby and Lichter, 2007); the section Nigri is the most common on grapes, including the species $A$. carbonarius, A. niger, A. tubingensis, and A. welwitschiae (Perrone et al., 2007). Alternaria spp. have also been reported as responsible for pre- and postharvest losses of agricultural commodities, including grapes (Lorenzini and Zapparoli, 2014; Garganese et al., 2016), with A. alternata as most recurrent species (Stocco et al., 2019).

These fungi have additional important detrimental roles, being able to produce mycotoxins. Mycotoxin production is highly influenced by climatic conditions (e.g., temperature and humidity), berry characteristics (e.g., $\mathrm{pH}$ and available water), fungicide applications, and harvesting and storage conditions (Covarelli et al., 2012). The main mycotoxin produced by Aspergillus spp. on grapes and consequently grape-derived products is ochratoxin A (OTA), which is primarily produced by $A$. carbonarius, although $A$. niger and $A$. welwitschiae also contribute to contamination (de Souza Ferranti et al., 2018). Aspergillus spp., including A. niger and A. welwitschiae, are also able to produce fumonisins (mostly $\mathrm{FB}_{2}$ ) (Samson et al., 2007; Hong et al., 2013). OTA is immunotoxic, nephrotoxic and possibly carcinogenic
(IARC, 1993), so that the European Commission set its maximum limits in foodstuffs deriving from grapes (EC, 2006). Fumonisins, although reported to be possibly carcinogenic (IARC, 1993), are regulated in the EU only on cereals and derived products (EC, 2007). The main mycotoxin produced by Penicillium spp. (particularly $P$. expansum) on fruits is patulin, which has been mainly reported on pome fruits, but is associated with several other crops including grapes (Sanzani et al., 2013, 2016b). Patulin content is regulated in apple-derived products in the EU (EC, 2006); however, no official regulatory limits exist for grapes and derived products. Not less important is contamination by Alternaria and its related toxins, which have been reported on several commodities, including grapes, both in the field and during storage (Sanzani et al., 2016a). The most relevant of these mycotoxins are tenuazonic acid $(\mathrm{TeA})$, alternariol $(\mathrm{AOH})$ and alternariol monomethyl ether (AME) (Wenderoth et al., 2019). Although Alternaria toxins can cause adverse effects in human and animal systems (Schuchardt et al., 2014), no regulatory limits exist for these compounds. Nevertheless, EFSA (2011) published a scientific opinion on the risks for animal and public health related to the presence of Alternaria toxins in feed and food.

Among the different practices for the control of postharvest rots during storage, given the lack or limited use of conventional fungicides, $\mathrm{SO}_{2}$ generating pads in packages remain an important tool due to their practicality, efficiency, low cost, and low health risks compared to fungicides (Franck et al., 2005).

The table grape production chain in Lebanon encounters many of these phytosanitary problems. Most important are postharvest rots, which result from poor practices in the field, at harvesting, and during storage. The aims of the present study were: i) to assess the fungal populations associated with table grapes in Lebanese packinghouses; ii) to determine the effects of storage conditions on the fungal populations; iii) to characterize at the species level the populations of the most represented mycotoxigenic genera; and iv) to molecularly characterize the putative ability of fungi to produce relevant mycotoxins.

\section{MATERIALS AND METHODS}

Assessments of the fungal population on table grape bunches by the end of storage

\section{Sampling}

Table grapes samples were collected from five packinghouses located in Central Bekaa district (Bekaa 
region, Lebanon), which apply room cooling systems, during February 2020. The grapes had been stored for three months at $1 \pm 2^{\circ} \mathrm{C}, 95 \%$ relative humidity (RH), and with $\mathrm{SO}_{2}$ generating pads. In each facility, the two most abundant cultivars were selected for sampling. For each cultivar, a sample of 15 bunches was randomly taken from at least five boxes, the bunches were transported in refrigerated containers to the laboratory, and were processed within a maximum of $12 \mathrm{~h}$.

Assessment of epiphytic populations

From each sample, three replicates of 20 berries each were randomly taken and placed separately in a sterile plastic bag containing $200 \mathrm{~mL}$ of $0.05 \%$ Tween 20 (Sigma Aldrich). Replicates were shaken for $30 \mathrm{~min}$ on an orbital shaker at $150 \mathrm{rpm}$. For each replicate, aliquots of 200 $\mu \mathrm{L}$ were then plated on three Petri plates (90 mm diam.) containing Dichloran Glycerol 18\% Agar (DG18, Deben Diagnostics Ltd), and these were incubated for 3-5 d in the dark at $24 \pm 1^{\circ} \mathrm{C}$ (Aşkun et al., 2007). Fungal colonies were then counted, and the associated epiphytic population was expressed as Colony Forming Units per gram of fresh berry weight (CFU g-1 fbw).

Assessment of latent infections by fungal pathogens

For each sample, three replicates of 20 berries each were surface decontaminated by soaking in $2 \% \mathrm{NaOCl}$ solution for $2 \mathrm{~min}$, rinsed with sterile distilled water for $2 \mathrm{~min}$, and then dried under a laminar flow hood. Each replicate was aseptically placed in a sterile plastic bag and kept at $-20 \pm 1^{\circ} \mathrm{C}$ for $2 \mathrm{~h}$ to facilitate the collapse of the berry tissues (Sanzani et al., 2012). The bags were then placed in an incubator at $24 \pm 1^{\circ} \mathrm{C}$ in the dark for a maximum of $7 \mathrm{~d}$. Berries showing signs of fungal infections were counted and the incidence of latent infections expressed as percentage (\%) of symptomatic berries. The recovered fungal colonies were identified based on the morphological characteristics (Barnett and Hunter, 1999), and the frequency of each genus was calculated as percentage of the total recovered colonies.

\section{Assessment of rots}

In each packinghouse and for each cultivar, five boxes were inspected at the end of storage. Each bunch was visually checked for the presence of rot symptoms. Disease severity was assessed using an empirical scale of eight classes: 0 = sound cluster; 1 = one-two infect- ed berries; $2=$ three-five infected berries; $3=$ six-ten infected berries; $4=$ less than $25 \%$ infected cluster; 5 $=26-50 \%$ infected cluster; $6=51-75 \%$ infected cluster; and $7=$ more than $76 \%$ infected cluster. The average severity scale was then calculated and the disease severity index (DSI) was determined using the following equation: DSI $(\%)=[$ sum (class frequency $\times$ score of rating class)] [(total number of clusters $) \times$ (maximal disease index) $]^{-1} \times 100$ (Chiang et al., 2017).

\section{Effects of storage conditions on the fungal populations}

To study the effects of storage conditions on the fungal populations, particularly the use of $\mathrm{SO}_{2}$ generating pads, samples of 15 bunches of 'Red Globe' and 'Crimson' grapes were collected from one packinghouse in Ferzoul (Packinghouse 2) after packing and just before pre-cooling $\left(\mathrm{T}_{0}\right)$ and at the end of the storage period $\left(\mathrm{T}_{\mathrm{f}}\right)$. Sampling was made from packages in which an $\mathrm{SO}_{2}$ pad was present $\left(+\mathrm{SO}_{2}\right)$ and from packages that underwent the same storage conditions but without $\mathrm{SO}_{2}$ pads $\left(-\mathrm{SO}_{2}\right)$. Epiphytic fungal populations, latent infections, and rots were evaluated as described above.

\section{Characterization of toxigenic fungal pathogens}

From each trial, a representative number of fungal isolates, belonging to the toxigenic genera Aspergillus, Penicillium, and Alternaria, was collected for subsequent characterization at species level, according to, respectively, Samson et al. (2014), Visagie et al. (2014), and Woudenberg et al. $(2013 ; 2015)$. Monoconidial isolates were obtained by spreading conidium suspensions on $2.5 \%$ water agar and collecting single germinated spores using stereomicroscope observation. Isolates were stored at $4 \pm 1^{\circ} \mathrm{C}$ on slants of Potato Dextrose Agar (PDA, Himedia).

\section{DNA extraction}

For each fungal isolate, five mycelium plugs were collected from 7-d-old PDA colonies, and used to inoculate Malt Extract Agar (MEA, Fluka) in Petri plates with the agar surfaces overlapped by sterilized cellophane disks. After incubation at $24 \pm 1^{\circ} \mathrm{C}$ for $2-3 \mathrm{~d}$, the layers of fresh hyphae were removed using a scraper, and were placed in $2 \mathrm{~mL}$ capacity microcentrifuge tubes and stored at $-20 \pm 1^{\circ} \mathrm{C}$. DNA extraction was carried out according to Murray and Thompson (1980) as modified by Rogers and Bendich (1989) with further slight 
modifications. Briefly, two iron balls (5 $\mathrm{mm}$ diam.) were added to $100 \mathrm{mg}$ of mycelium followed by liquid nitrogen. Once nitrogen evaporated, the tubes were placed in a tissue lyser (Qiagen) at maximum frequency (30 osc s${ }^{-1}$ ) for $45 \mathrm{~s}$. For each isolate, $600 \mu \mathrm{L}$ of CTAB buffer (100 mM Tris- $\mathrm{HCl} \mathrm{pH}$ 8.0, $1.4 \mathrm{M} \mathrm{NaCl}, 20 \mathrm{mM}$ EDTA, $0.2 \% \beta$-mercaptoethanol, $2 \%$ CTAB) (previously kept at $75 \pm 1^{\circ} \mathrm{C}$ for $30 \mathrm{~min}$ ) were added to the sample and mixed gently. The samples were then frozen and defrozen three times, using liquid nitrogen and a water bath at $75 \pm 1^{\circ} \mathrm{C}$. The samples were then kept in the water bath for $60 \mathrm{~min}$ at $75 \pm 1^{\circ} \mathrm{C}$ (inverted every $10 \mathrm{~min}$ ). The tubes were then cooled, and $600 \mu \mathrm{L}$ of chloroform were added to samples and vortexed. The tubes were then centrifuged at $14,000 \mathrm{rpm}$ for $15 \mathrm{~min}$, the liquid phase was transferred into new microcentrifuge tubes each containing 2 volumes of isopropanol, and the tubes were each inverted gently. The samples were maintained at $-80 \pm 1^{\circ} \mathrm{C}$ for $30 \mathrm{~min}$, and then centrifuged at $14,000 \mathrm{rpm}$ and $4 \pm 1^{\circ} \mathrm{C}$ for $20 \mathrm{~min}$. Each resulting pellet was washed with $200 \mu \mathrm{L} 70 \%$ ethanol and centrifuged for $5 \mathrm{~min}$ in the same conditions. The pellets were then air-dried and re-suspended in $200 \mu \mathrm{L}$ TE buffer ( $\mathrm{pH}$ 8.0). The extract- ed DNA was quantified by a Nanodrop (Shimadzu) and diluted to $25 \mathrm{ng} \mu \mathrm{L}^{-1}$.

High Resolution Melting assays to screen Penicillium and Aspergillus isolates

To screen the isolates belonging to Penicillium and Aspergillus, genus-specific primer pairs (Table 1), synthesized by Macrogen, were used in High Resolution Melting (HRM) reactions, run in a CFX96 Touch Real-time PCR Detection System (Bio-Rad) and analysed using CFX-Manager Software v1.6 (Bio-Rad), as reported by Mincuzzi et al. (2020). A cut-off genotype confidence percentage (GCP) $\geq 95 \%$ was set for assigning isolates to genotypes.

Molecular identification of fungi

All Alternaria $(\mathrm{n}=$ eight) isolates, and representative isolates of Penicillium $(\mathrm{n}=\mathrm{six})$ and Aspergillus $(\mathrm{n}=$ ten) selected based on the clusters obtained with HRM assays (at least one isolate per cluster) were sub-

Table 1. Primers for HRM screening, sequencing, and mycotoxin gene detection of Penicillium, Aspergillus and Alternaria isolates from grape samples.

\begin{tabular}{|c|c|c|c|c|c|}
\hline Genus & $\begin{array}{l}\text { Gene/ } \\
\text { Region }\end{array}$ & Primer name & Sequence $\left(5^{\prime}-3^{\prime}\right)$ & Amplicon size (bp) & Source \\
\hline \multirow[t]{6}{*}{ Penicillium } & $\beta$-tubulin & $\mathrm{Bt} 2 \mathrm{a}$ & GGTAACCAAATCGGTGCTGCTTTC & 330 & Glass and Donaldson, 1995 \\
\hline & & $\mathrm{Bt} 2 \mathrm{~b}$ & ACCCTCAGTGTAGTGACCCTTGGC & & \\
\hline & & PPF1 & GAGCGYATGAACGTCTACTT & 130 & Mincuzzi et al., 2020 \\
\hline & & PPR1 & ACVAGGACGGCACGGGGAAC & & \\
\hline & msas & Pe $11 F$ & CACTTATTGTGACCCGCAGA & 288 & Sanzani et al., 2009 \\
\hline & & Pe $12 \mathrm{R}$ & CTCGAAGAGGATCCATGAGG & & \\
\hline \multirow[t]{12}{*}{ Aspergillus } & calmodulin & CMD5 & CCGAGTACAAGGARGCCTTC & 520 & Hong et al., 2005 \\
\hline & & CMD6 & CCGATRGAGGTCATRACGTGG & & \\
\hline & & HRM-CMDF & ATAGGACAAGGATGGCGATG & 205 & Mincuzzi et al., 2020 \\
\hline & & HRM-CMDR & AGACTCGGAGGGGTTCTGGC & & \\
\hline & fum8 & FUM8F & TTCGTTTGAGTGGTGGCA & 651 & Susca et al., 2014 \\
\hline & & FUM8R & CAACTCCATASTTCWWGRRAGCCT & & \\
\hline & fum15 & FUM15F & CGATTGGTAGCCCGAGGAA & 701 & \\
\hline & & FUM15R & CTTGATATTGCGGAGTGGTCC & & \\
\hline & otal & OTA1F & CAATGCCGTCCAACCGTATG & 776 & Susca et al., 2016 \\
\hline & & OTA1R & CCTTCGCCTCGCCCGTAG & & \\
\hline & ota3 & OTA3F & TTAGACAAACTGCGCGAGGA & 613 & \\
\hline & & OTA3R & GCGTCGCTATGCCCAGATA & & \\
\hline \multirow[t]{4}{*}{ Alternaria } & OPA1-3 & OPA1-3L & CAGGCCCTTCCAATCCAT & 900 & Peever et al., 2004 \\
\hline & & OPA1-3R & AGGCCСTTCAAGCTCTCTTC & & \\
\hline & pksI & pksI-F & ССТСТСТАТСССАААСТССАСАС & 249 & Sanzani et al., 2021 \\
\hline & & pksI-R & CACAGATTATGGCAAGGTTC & & \\
\hline
\end{tabular}


Table 2. Reference strains used in phylogenetic analyses and their GenBank accession numbers.

\begin{tabular}{llll}
\hline Genus & \multicolumn{1}{c}{ Species } & \multicolumn{1}{c}{ Strain } & Accession No. \\
\hline Alternaria & A. alternata & CBS 112249 & MG063725 \\
& & CBS 116329 & MF070417 \\
& A. arborescens & A214 & MK204937 \\
& A. solani & ASOL & KU933224 \\
\hline Aspergillus & A. flavus & CBS117733 & KY561993 \\
& A. nidulans & CBS 100522 & KX423636 \\
& A. porosus & CBS 375.75 & LT671137 \\
& A. tubingensis & AS5 & MK919489 \\
& & AS18 & MK919490 \\
& A. uvarum & DTO 178-B5 & KP330146 \\
& A. welwitschiae & AS23 & MK919493 \\
& & AS28 & MK919491 \\
& & CBS 139.54 & KK919492 \\
& & 942 & MH614648 \\
\hline Penicillium & P. brevicompactum & CMV006A8 & MK451072 \\
& & G14 & MK895703 \\
P. chrysogenum & CBS 109613 & KJ866978 \\
& CBS 48184 & AY674399 \\
& DTO 057-A5 & KM08875 \\
& CBS 38175 & AY674444 \\
\hline
\end{tabular}

jected to sequencing of portions of barcoding genes, using the primer pairs detailed in Table 1 . PCR reactions were each carried out using $1 \times$ Ready Master Mix (Qiagen), $1.5 \mathrm{mM} \mathrm{MgCl}_{2}, 0.2 \mu \mathrm{M}$ of each primer, and $25 \mathrm{ng}$ of DNA template in a final volume of $25 \mu \mathrm{L}$. The amplifications were carried out in a T100 MyCycler thermal cycler (Bio-Rad) using the following conditions: $2 \mathrm{~min}$ at $95^{\circ} \mathrm{C}$, followed by 40 cycles of $30 \mathrm{~s}$ at $95^{\circ} \mathrm{C}, 30 \mathrm{~s}$ at $55-58^{\circ} \mathrm{C}, 50 \mathrm{~s}$ at $72^{\circ} \mathrm{C}$, and $5 \mathrm{~min}$ at $72^{\circ} \mathrm{C}$. After this, $10 \mu \mathrm{L}$ of each PCR product were loaded on a $1.5 \%$ agarose gel in $1 \times$ TAE buffer and visualized by the imager system Gel Doc 1000 (Bio-Rad). Purification of PCR products was then carried out using the QIAquick Gel Extraction Kit (Qiagen) following manufacturer's instructions. Purified PCR products were sequenced in both directions by the Medical Genetics Unit at Saint Joseph University (Beirut, Lebanon). For species identification, all sequences were aligned through Chromas software (https://chromas.software.informer.com/ download/) and compared with the available sequences in NCBI BLAST database. Subsequently, using MEGA$\mathrm{X}$ software (https://www.megasoftware.net/dload_win_ gui), phylogenetic trees were constructed using the Maximum Likelihood method (Kumar et al., 2018), accord- ing to the Tamura-Nei model (1993) with 1000 bootstrap replications. Reference and CBS strains were included (Table 2).

Molecular characterization of putative ability to produce mycotoxins

According to genus and species, the strains were tested for the presence of genes involved in biosynthetic pathways of the most relevant mycotoxins. The assayed genes were: pksI for $\mathrm{AOH} / \mathrm{AME}$ biosynthesis, assayed for Alternaria strains; otal/ota3 for OTA and fum8/ fum 15 for fumonisin biosynthesis, assayed for Aspergillus strains; and msas for patulin biosynthesis, assayed for Penicillium strains. Primers, reported in Table 1, were synthesized by Eurofins Genomics. PCR mixtures were each of $25 \mu \mathrm{L}$, containing $25 \mathrm{ng}$ of DNA, $0.2 \mu \mathrm{M}$ of each primer, and $1 \times$ Dream Taq Hot Start Green PCR Master Mix (Thermo Fischer Scientific); reactions were carried out according to authors' conditions (Table 1). The presence/absence of these genes was estimated by running an amplicon aliquot on $1.5 \%$ agarose gel and UV visualization.

\section{Statistical analyses}

Statistical analyses were carried out using IBM SPSS software (version 23). One-way Analysis of Variance (ANOVA) was performed to verify the significance of differences between means, and means were separated using Duncan's Multiple Range test (DMRT).

\section{RESULTS}

Epiphytic fungal populations, latent infections, and severity of grape berry decay

Table grapes from five table grape packinghouses in different Lebanese areas were assessed for epiphytic populations of filamentous fungi, latent infections, and rots at the end of storage. Two cultivars from each packinghouse were inspected. Assessment of the epiphytic populations (Table 3) showed low $\mathrm{CFU} \mathrm{g} \mathrm{g}^{-1} \mathrm{fbw}$ values. Particularly, from 'Autumn King' and 'Superior' samples from Packinghouse 1 (Zahlé area) and 'Crimson' from Packinghouse 4 (Chtaura area), no fungal colonies were recovered. In the other cases, the total fungal counts varied from 1 to $64 \mathrm{CFU} \mathrm{g}^{-1} \mathrm{fbw}$. Significant differences $(P \leq 0.05)$ were determined between the cultivars in the different packinghouses. 
Table 3. Mean epiphytic fungal populations, latent infections and disease severities on table grapes from different packinghouses in Bekaa region (Lebanon) at the end of storage.

\begin{tabular}{|c|c|c|c|c|c|c|}
\hline \multirow{2}{*}{ Packinghouse } & \multirow{2}{*}{ Locality } & \multirow{2}{*}{ Cultivar } & \multirow{2}{*}{$\begin{array}{l}\text { Epiphytic population } \\
\left(\mathrm{CFU} \mathrm{g}^{-1} \mathrm{fbw}\right)^{*}\end{array}$} & \multirow{2}{*}{$\begin{array}{l}\text { Latent infections } \\
(\%)^{\star}\end{array}$} & \multicolumn{2}{|c|}{ Disease severity } \\
\hline & & & & & Scale $^{*}$ & $\mathrm{DSI}^{\star *}(\%)$ \\
\hline \multirow[t]{2}{*}{1} & \multirow[t]{2}{*}{ Zahlé } & Autumn King & $0 \mathrm{c}$ & $10.0 \pm 8.2 \mathrm{a}$ & $1.7 \pm 0.3 \mathrm{a}$ & 24.8 \\
\hline & & Superior & $0 \mathrm{c}$ & $11.7 \pm 2.7 \mathrm{a}$ & $0.6 \pm 0.2 \mathrm{bc}$ & 8.6 \\
\hline \multirow[t]{2}{*}{2} & \multirow[t]{2}{*}{ Ferzoul } & Crimson & $24 \pm 9 a$ & $10.0 \pm 0.0 \mathrm{a}$ & $0.8 \pm 0.2 \mathrm{bc}$ & 11.4 \\
\hline & & Red Globe & $4 \pm 4 \mathrm{bc}$ & $10.0 \pm 4.7 \mathrm{a}$ & $0.2 \pm 0.1 \mathrm{c}$ & 2.9 \\
\hline \multirow[t]{2}{*}{3} & \multirow[t]{2}{*}{ Zahlé } & Black Pearl & $34 \pm 24 \mathrm{a}$ & $6.7 \pm 1.4 \mathrm{a}$ & $0.3 \pm 0.1 \mathrm{c}$ & 4.8 \\
\hline & & Red Globe & $19 \pm 16 \mathrm{ab}$ & $8.3 \pm 6.9 \mathrm{a}$ & $1.2 \pm 0.2 \mathrm{ab}$ & 17.1 \\
\hline \multirow[t]{2}{*}{4} & \multirow[t]{2}{*}{ Chtaura } & Autumn King & $64 \pm 35 a$ & $15.0 \pm 7.1 \mathrm{a}$ & $0.8 \pm 0.2 \mathrm{bc}$ & 11.4 \\
\hline & & Crimson & $0 \mathrm{c}$ & $6.7 \pm 1.4 \mathrm{a}$ & $1.1 \pm 0.3 \mathrm{ab}$ & 16.2 \\
\hline \multirow[t]{2}{*}{5} & \multirow[t]{2}{*}{ Zahlé } & Chile & $3 \pm 3 b c$ & $0 \mathrm{~b}$ & $0.1 \pm 0.1 \mathrm{c}$ & 1.0 \\
\hline & & Crimson & $1 \pm 1 \mathrm{c}$ & $0 \mathrm{~b}$ & $0.3 \pm 0.1 \mathrm{c}$ & 3.8 \\
\hline
\end{tabular}

* Means \pm standard errors. In each column, values accompanied by different letters are significantly different $(P \leq 0.05)$.

${ }^{*}$ DSI $=$ Disease severity index.

For example, samples of 'Autumn King' from two different packinghouses showed the opposite extreme values. Occurrence of latent infections at the end of the storage was evaluated (Table 3). Four packinghouses and related cultivars showed latent infection incidence varying from 6.7\% on 'Black pearl' (Packinghouse 3) and 'Crimson' (Packinghouse 4) to $15 \%$ on 'Autumn King' (Packinghouse 4). The most frequent fungal genera causing latent infections were Penicillium (47.1\%), followed by Botrytis (29.4\%), Alternaria (7.8\%), Aspergillus (5.9\%), Stemphylium (4.0\%), Cladosporium (3.9\%), and other fungi (2.0\%). Disease severity on bunches was measured at the end of storage in all packinghouses (Table 3). Significant differences were observed between the mean disease severities. The greatest severity (mean $=1.7$, range $0-7$ ) was recorded on 'Autumn King' samples from Packinghouse 1 (mean DSI $=24.8 \%$ ), whereas the least severity (mean $=0.1)$ was detected on 'Chile' from Packinghouse 5 (mean DSI $=1 \%$ ). In general, Botrytis was the predominant genus observed on stored bunches.

\section{Effects of storage conditions on the fungal populations}

Effects of the use of $\mathrm{SO}_{2}$ generating pads were evaluated in Packinghouse 2, on 'Red Globe' and 'Crimson'. Large reductions in the epiphytic fungal populations on 'Red Globe' (97.9\%) and 'Crimson' (99.3\%) was detected between $\mathrm{T}_{0}$ (beginning of storage) and $\mathrm{T}_{\mathrm{f}}$ (end of storage) in presence of $\mathrm{SO}_{2}$ pads (Figure 1). Penicillium growth was reduced by up to $99 \%$. For Aspergillus, which was less than Penicillium at $\mathrm{T}_{0}$, growth was completely pre- vented at $\mathrm{T}_{\mathrm{f}}$ (Figure $1 \mathrm{a}$ and $\mathrm{b}$ ). However, the effect of $\mathrm{SO}_{2}$ during storage on latent infections was variable, being effective on 'Red Globe' but not on 'Crimson'. Although $\mathrm{SO}_{2}$ completely prevented Botrytis infections on both cultivars, it did not influence Aspergillus and Penicillium infections on 'Crimson' berries (Figure $1 \mathrm{c}$ and d).

As confirmation, the effects of $\mathrm{SO}_{2}$ were evaluated after three months of storage in the same packinghouse on boxes stored with or without $\mathrm{SO}_{2}$ pads (Figures 2 and 3). Results confirmed the potential of the pads for reducing total latent infections (Figure 2). In the absence of pads, mean incidence of total latent infections at the end of storage was $31.7 \%$ on 'Red Globe' and $37.5 \%$ on 'Crimson', whereas in boxes stored with $\mathrm{SO}_{2}$ pads, mean incidence was $10 \%$ on both cultivars. $\mathrm{SO}_{2}$ generating pads completely prevented latent infections caused by Botrytis and Alternaria, whereas latent infections by Penicillium were observed in both types of packages, with mean incidence varying between 10 and $16.7 \%$. Similarly, decay severity assessed after 3 months of storage on both cultivars was greater $(P \leq 0.05)$ in boxes stored without $\mathrm{SO}_{2}$ pads than in boxes containing the pads (Figure 3).

Characterization of fungal strains and their putative abilities to produce mycotoxins

During the assessments of epiphytic fungal populations, latent infections, and rots, three genera among mycotoxigenic fungi were identified: Alternaria, Aspergillus, and Penicillium. A total of 44 isolates were col- 

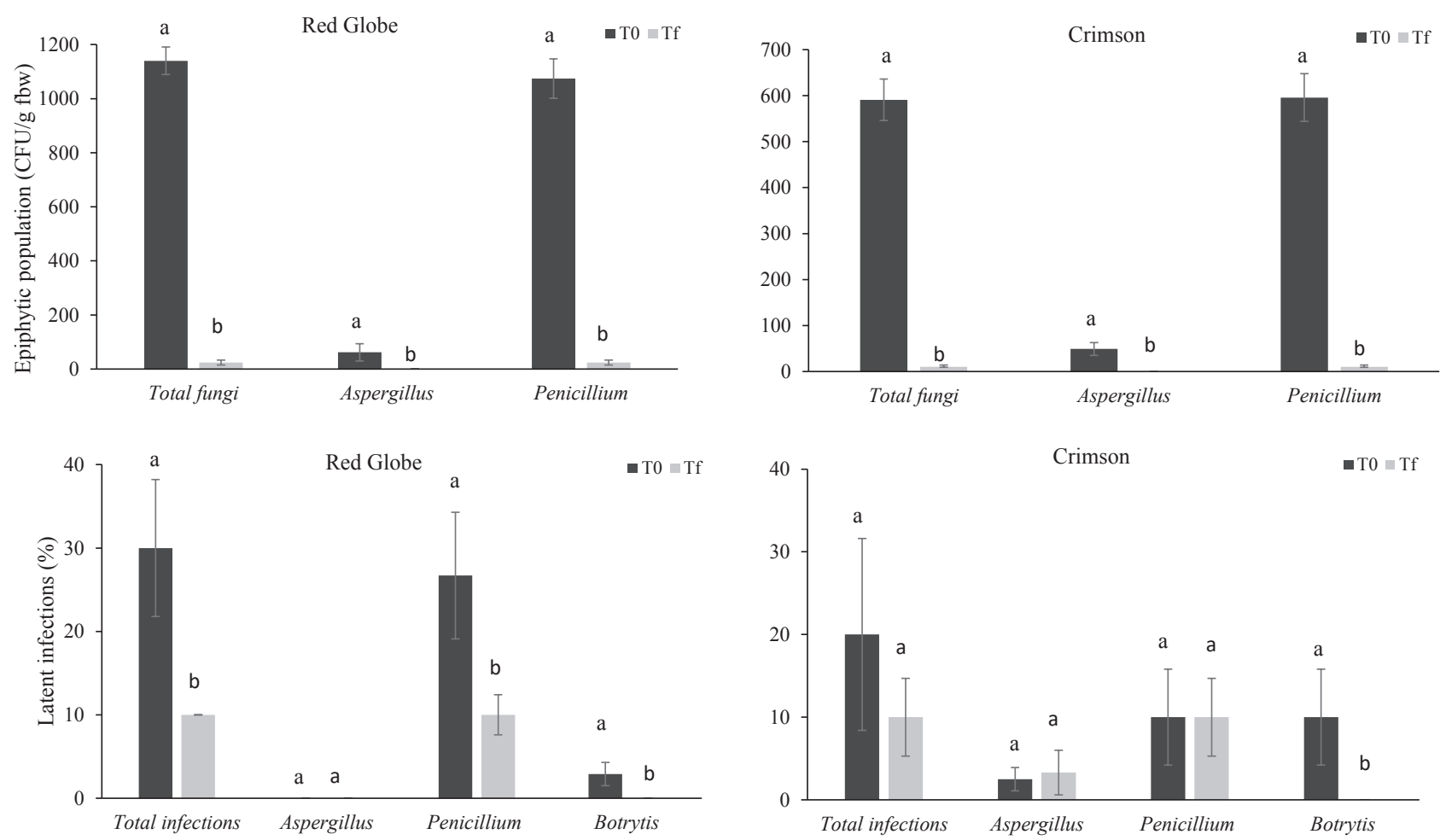

Figure 1. Mean populations of epihytic fungi, and proportions (\%) of latent fungal infections, on 'Red Globe' and 'Crimson' table grapes, stored with $\mathrm{SO}_{2}$ generating pads. For each variable, mean values at $\mathrm{T}_{0}$ (black histogram, beginning of storage) and $\mathrm{T}_{\mathrm{f}}$ (end of storage) accompanied by different letters are significantly different $(P \leq 0.05)$. Bars represent standard errors of means, each from three replicates.

lected according to morphology and frequency of isolations. Twenty-four isolates were Aspergillus, 12 were Penicillium, and eight were Alternaria. All the isolates were assigned to a species according to morphological features on specific media and sequencing of barcoding genes/regions. Aspergillus and Penicillium isolates were the most abundant so these were initially screened by HRM to identify genetic clusters. For at least one isolate per cluster of Aspergillus, a portion of the calmodulin gene was sequenced, whereas for Penicillium, a portion of the $\beta$-tubulin gene was sequenced. Sequences were run against those in the GenBank database, and they showed $99-100 \%$ identity with relevant reference sequences. As further confirmation, a phylogenetic analysis was conducted including CBS and reference strains (Figures 4, 5 and 6).

For Aspergillus, all strains belonged to section Nigri and were divided into ten clusters (Table 4, Figure 4). Most of isolates belonged to series Nigri, being A. tubingensis $(67 \%)$ and A. welwitschiae (12\%), and the remaining were in series Japonici, as A. uvarum (21\%). For $A$. welwitschiae strains (AS20, AS27, and AS31), the presence of key biosynthetic genes for OTA (ota1 and ota3) and fumonisins (fum 8 and fum15) was assessed. Strains A27 and AS31, belonging to the same HRM cluster (9), possessed ota3 and fum15 genes, so were potential producers of OTA and fumonisins, while strain AS20 (HRM cluster 7) did not possess these genes (Table 4).

For Penicillium (Table 5, Figure 5), five HRM clusters were identified corresponding to three sections. The most abundant was sect. Aspergilloides with $50 \%$ of the strains identified as P. glabrum, followed by sect. Brevicompacta with $P$. brevicompactum (25\%) and P. olsonii (17\%), and sect. Penicillium with $P$. expansum (8\%). $P$ expansum strain P18 possessed msas, the key gene for patulin biosynthesis (Table 5).

For Alternaria, A. alternata and the A. arborescens species complex were identified (Table 6). Isolate identity was supported by a phylogenetic analysis, including CBS and references strains (Figure 6). Eighty-eight percent of the strains were A. alternata morphotype alternata, and $12 \%$ were in the $A$. arborescens species complex. Strains were tested for the presence of the pksI gene for alternariol biosynthesis and all were potential AOH/AME producers (Table 6). 

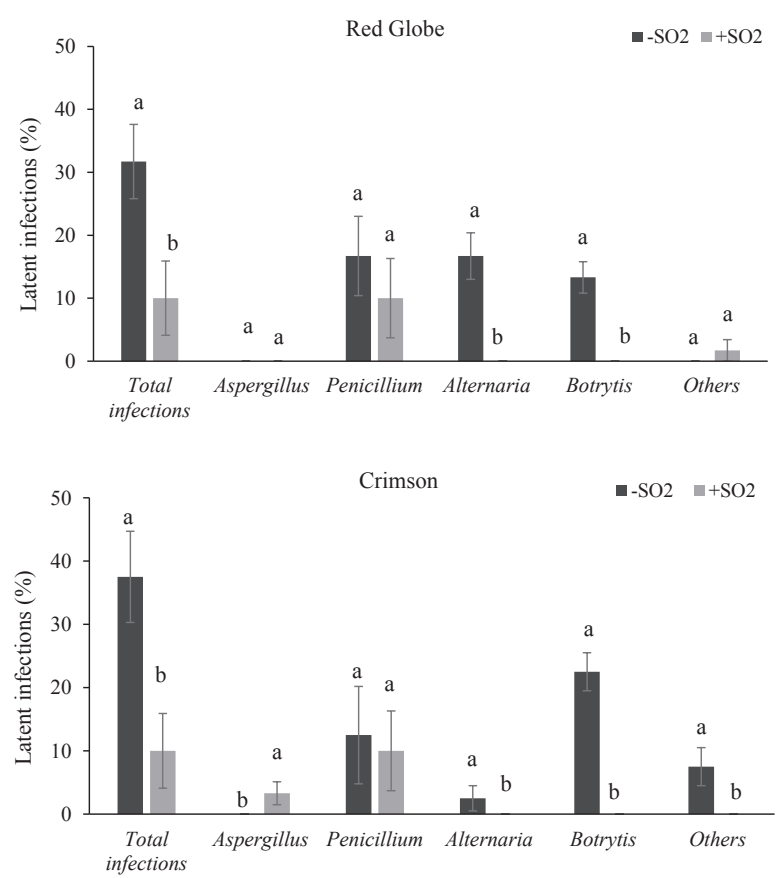

Figure 2. Mean proportions (\%) of latent fungal infections on 'Red Globe' and 'Crimson' table grapes, stored either with $\left(+\mathrm{SO}_{2}\right)$ or without (black histograms, $-\mathrm{SO}_{2}$ ) $\mathrm{SO}_{2}$ pads, after three month of storage. For each variable, columns accompanied by different letters are significantly different $(P \leq 0.05)$. Bars represent standard errors of mean, each from three replicates.

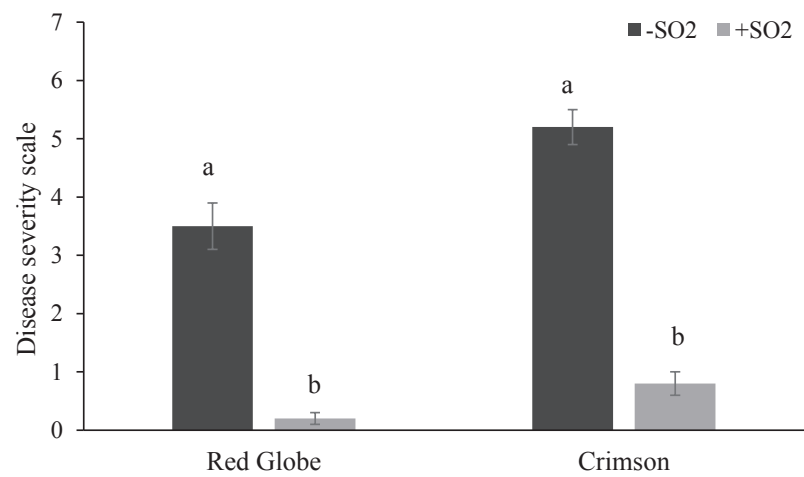

Figure 3. Disease severity (scale $0-7$ ) on 'Red Globe' and 'Crimson' table grapes, stored either with $\left(+\mathrm{SO}_{2}\right)$ or without (black histograms, $\left.-\mathrm{SO}_{2}\right) \mathrm{SO}_{2}$ pads, after three month of storage. Columns accompanied by different letters are significantly different $(P \leq 0.05)$. Bars represent standard errors of means, each from three replicates.

\section{DISCUSSION}

Crops of table grapes are of increasing importance in Lebanon. However, there is little information available on the main fungal pathogens affecting table grape storability. The present study was conducted to col- lect information on the main threats to harvested table grapes, with particular attention on mycotoxigenic fungi. Five packinghouses were inspected in different areas of Lebanon for epiphytic fungal populations, latent infections, and rots. The study showed that Botrytis, Penicillium, Aspergillus, and Alternaria were the most abundant genera. These results are in line with other studies. Ding et al. (2019) reported epiphytic populations on grapes in subtropical China, and indicated that Cladosporium, Penicillium, Aspergillus, and Alternaria were among the most abundant fungi. Similarly, Oliveira et al. (2017) showed that these genera were the most frequently isolated from grape berries in Portugal. They also stressed the influence of atmospheric conditions on the composition of the fungal community detected. Abdelfattah et al. (2019) reported exchanges between grape plants and the surrounding environment, so that grape plants could be major sources of recruitment for the atmospheric microbiome.

Aspergillus and Penicillium species are considered to be the most important wound pathogens. They commonly enter host plants through wounds and natural openings. Wounds can be created at pre- and postharvest stages, especially if the products are subjected to improper handling either at harvesting or during packing and storage operations (Mincuzzi et al., 2020). In the present study, different packinghouses were assessed, each with two grape cultivars. Although the epiphytic fungal populations were generally low, some differences were observed. For example, despite the same storage procedures, including air cooling and the use of $\mathrm{SO}_{2}$ generating pads in the two different packinghouses, the grapes of 'Autumn King' and 'Crimson' had different amounts of contamination. This could be due to different field inoculum loads and composition. The present study showed different susceptibilities to $\mathrm{SO}_{2}$ among fungi, with Botrytis more susceptible to $\mathrm{SO}_{2}$ than Penicillium. Furthermore, the different responses among cultivars could be related to features such as berry epidermis thickness or compaction, cell wall thickness, and/ or epidermis microstructure (Fernández-Trujillo et al., 2012). Influences of vineyard management on epiphytic microbial composition could also be involved (Abdelfattah et al., 2019).

Latent fungal infections were present on most of the cultivars. These results are not surprising since Botrytis is well known for its ability to infect grapevine from the flowering stage, and can remain latent/dormant until reactivation following suitable conditions (i.e., ripening and favourable environmental conditions; Sanzani et al., 2012). During packinghouse operations, berries may seem healthy, but eventually become rotted during 
Table 4. Aspergillus HRM clusters, species, strains, GenBank accession numbers for the calmodulin gene, and presence of ochratoxin A (ota1 and ota3) and fumonisins (fum 8 and fum 15) biosynthetic genes.

\begin{tabular}{|c|c|c|c|c|c|c|c|}
\hline \multirow{2}{*}{ HRM Cluster } & \multirow{2}{*}{ Species } & \multirow{2}{*}{ Strain } & \multirow{2}{*}{ Accession no.* } & \multicolumn{4}{|c|}{ Detection of biosynthetic genes ${ }^{* *}$} \\
\hline & & & & ota1 & ota3 & fum8 & fum 15 \\
\hline \multirow[t]{3}{*}{1} & A. tubingensis & AS17 & n.a. & n.a. & n.a. & n.a. & n.a. \\
\hline & & AS21 & MZ241120 & n.a. & n.a. & n.a. & n.a. \\
\hline & & AS24 & n.a. & n.a. & n.a. & n.a. & n.a. \\
\hline \multirow[t]{3}{*}{2} & A. tubingensis & AS15 & MZ241118 & n.a. & n.a. & n.a. & n.a. \\
\hline & & AS18 & n.a. & n.a. & n.a. & n.a. & n.a. \\
\hline & & AS22 & n.a. & n.a. & n.a. & n.a. & n.a. \\
\hline \multirow[t]{3}{*}{3} & A. tubingensis & AS2 & MZ241114 & n.a. & n.a. & n.a. & n.a. \\
\hline & & AS19 & n.a. & n.a. & n.a. & n.a. & n.a. \\
\hline & & AS25 & n.a. & n.a. & n.a. & n.a. & n.a. \\
\hline \multirow[t]{3}{*}{4} & A. tubingensis & AS14 & MZ241117 & n.a. & n.a. & n.a. & n.a. \\
\hline & & AS16 & MZ241119 & n.a. & n.a. & n.a. & n.a. \\
\hline & & AS23 & n.a. & n.a. & n.a. & n.a. & n.a. \\
\hline \multirow[t]{2}{*}{5} & A. tubingensis & AS9 & n.a. & n.a. & n.a. & n.a. & n.a. \\
\hline & & AS29 & MZ241121 & n.a. & n.a. & n.a. & n.a. \\
\hline \multirow[t]{5}{*}{6} & A. uvarum & AS1 & n.a. & n.a. & n.a. & n.a. & n.a. \\
\hline & & AS10 & MZ241125 & n.a. & n.a. & n.a. & n.a. \\
\hline & & AS11 & MZ241126 & n.a. & n.a. & n.a. & n.a. \\
\hline & & AS26 & MZ241127 & n.a. & n.a. & n.a. & n.a. \\
\hline & & AS28 & MZ241128 & n.a. & n.a. & n.a. & n.a. \\
\hline 7 & A. welwitschiae & AS20 & MZ241122 & - & - & - & - \\
\hline 8 & A. tubingensis & AS13 & MZ241116 & n.a. & n.a. & n.a. & n.a. \\
\hline \multirow[t]{2}{*}{9} & A. welwitschiae & AS27 & MZ241123 & + & - & + & - \\
\hline & & AS31 & MZ241124 & + & - & + & - \\
\hline 10 & A. tubingensis & AS12 & MZ241115 & n.a. & n.a. & n.a. & n.a. \\
\hline
\end{tabular}

${ }^{*}$ n.a. $=$ not analyzed.

** The presence of OTA and fumonisin biosynthetic genes was checked in A. welwitschiae strains. + = Present; - = Absent.

storage. Being situated within berry grape tissues, Botrytis rots might not be prevented by surface treatments such as the $\mathrm{SO}_{2}$ generated by the preservation pads. $\mathrm{SO}_{2}$ does not penetrate deeply into berry tissues/skins ( $\mathrm{Smi}$ lanick et al., 1990), especially the skins are particularly impenetrable. Thus, in the present study, rots, mostly caused by $B$. cinerea, were significantly reduced by $\mathrm{SO}_{2}$ pads, although not prevented. The reduced sensitivity of 'Crimson' to $\mathrm{SO}_{2}$ compared to 'Red Globe' may be a cultivar effect, or due to the extent or composition of pathogen contamination (i.e., presence of Penicillium and Aspergillus). However, Youssef et al. (2020) found that $\mathrm{SO}_{2}$ generating pads, even at different concentrations and release rates, could completely inhibit grape decay caused by $B$. cinerea, if combined with a field control strategy to reduce infections rate during grapevine growth. These field treatments should be scheduled from flowering, to reduce rots during cold storage of harvested grapes. Alternative treatments with little to no poten- tial harmful environmental effects have raised public interest. For example, protein hydrolysates (e.g., from soybean or casein) were tested with good results (Lachhab et al., 2016).

The toxigenic fungi contaminating harvested Lebanese table grapes included Aspergilli of section Nigri. A. tubingensis is known as a non-producer of OTA (Storari et al., 2012); A. uvarum is a relatively newly discovered species, mostly occurring on grapes and is not toxigenic (Somma et al., 2012); and A. welwitschiae produces OTA and fumonisins (Perrone and Gallo, 2016), as observed for 2 of the 3 strains in the present study. For Penicillium, strains of $P$. glabrum and $P$. brevicompactum were found, which, despite being reported to possess genes for patulin biosynthesis (Bokhari and Aly, 2009; Diaz et al., 2011), have recently been questioned for their ability to produce patulin (Frisvad, 2018). P. olsonii, quite common in confined environments but reported as a non-producer of patulin (Frisvad, 2018), was also present. In the pre- 


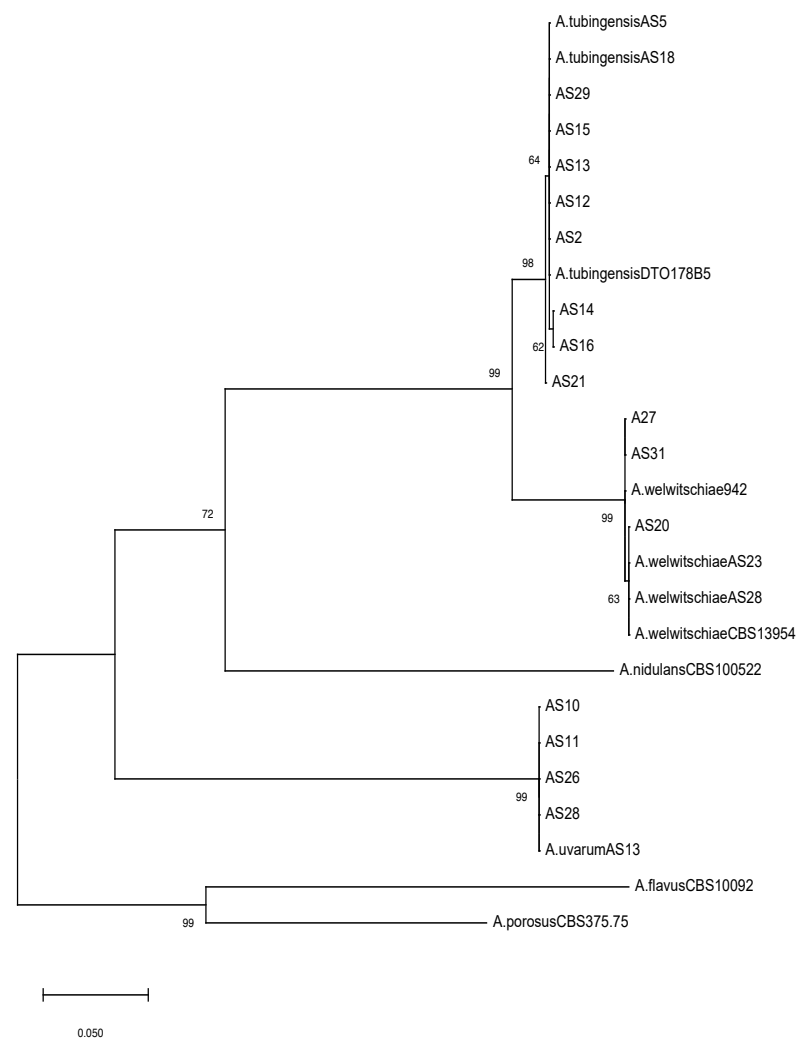

Figure 4. Phylogenetic tree for Aspergillus strains based on a portion of the calmodulin gene. Numbers on nodes represent the Maximum Likelihood bootstrap percentages. Branch lengths are proportional to the numbers of nucleotide substitutions and can be measured using the bar scale (0.05).

Table 5. Penicillium HRM clusters, species, strains, GenBank accession numbers for the $\beta$-tubulin gene, and presence of a patulin biosynthetic gene (msas).

\begin{tabular}{lcccc}
\hline $\begin{array}{l}\text { HRM } \\
\text { cluster }\end{array}$ & Species & Strain & Accession No. & $\begin{array}{c}\text { Detection of } \\
\text { msas }\end{array}$ \\
\hline 1 & P. glabrum & P6 & n.a. & n.a. \\
& & P7 & MZ241137 & n.a. \\
& & P8 & n.a. & n.a. \\
& & P9 & MZ241138 & n.a. \\
& & P10 & n.a. & n.a. \\
& & P11 & n.a. & n.a. \\
2 & P. brevicompactum & P14 & MZ241140 & n.a. \\
& & P17 & n.a. & n.a. \\
4 & P. brevicompactum & P13 & MZ241139 & n.a. \\
4 & P. olsonii & P12 & n.a. & n.a. \\
& & P16 & MZ241141 & n.a. \\
5 & P. expansum & P18 & MZ241142 & + \\
\hline
\end{tabular}

${ }^{*}$ n.a. $=$ not analyzed.

** The presence of patulin biosynthetic genes was checked in $P$. expansum strains. $+=$ Present; $-=$ Absent.

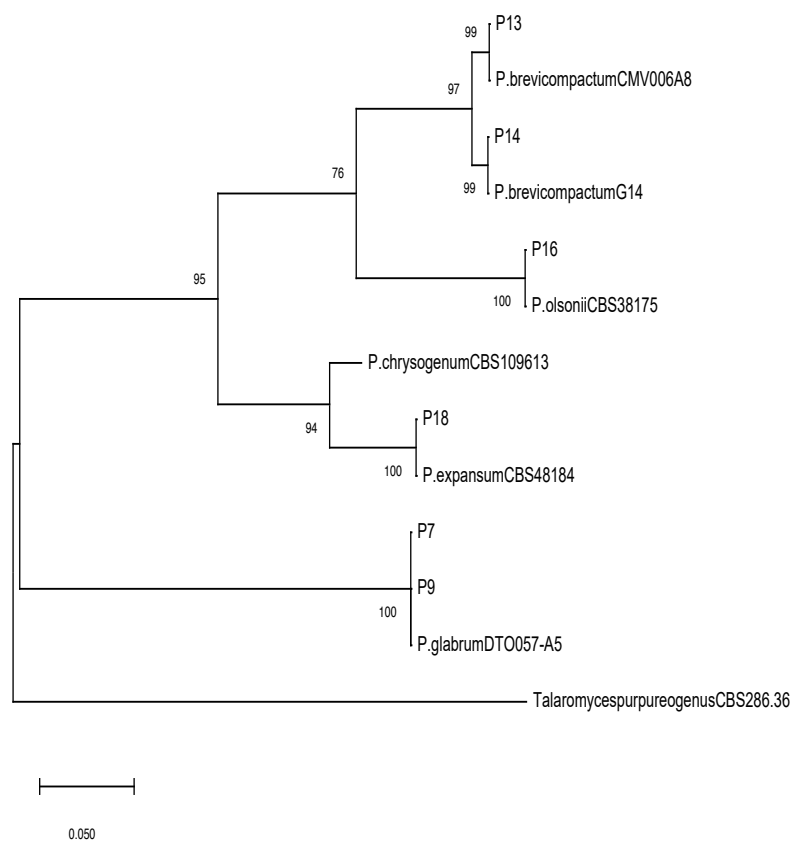

Figure 5. Phylogenetic tree for Penicillium strains based on a portion of the $\beta$-tubulin gene. Numbers on nodes represent the Maximum Likelihood bootstrap percentages. Branch lengths are proportional to the numbers of nucleotide substitutions and can be measured using the bar scale (0.05).

Table 6. Alternaria species/species complexes, morphotypes, strains, GenBank accession numbers for the OPA1-3 region, and presence of an alternariol biosynthetic gene $(p k s I)$.

\begin{tabular}{|c|c|c|c|c|}
\hline Species & Morphotype & Strain & Accession No. & $\begin{array}{c}\text { Detection of } \\
p k s I^{*}\end{array}$ \\
\hline A. arborescens & & Al1 & MZ241129 & + \\
\hline \multirow{7}{*}{ A. alternata } & alternata & $\mathrm{Al} 2$ & MZ241130 & + \\
\hline & & $\mathrm{Al} 4$ & MZ241131 & + \\
\hline & & $\mathrm{Al} 5$ & MZ241132 & + \\
\hline & & $\mathrm{Al} 7$ & MZ241133 & + \\
\hline & & Al11 & MZ241134 & + \\
\hline & & Al12 & MZ241135 & + \\
\hline & & Al16 & MZ241136 & + \\
\hline
\end{tabular}

${ }^{\star}+$ = Present; - = Absent.

sent study, a single strain of $P$. expansum able to produce patulin was detected, belonging to the species known as the most potent patulin producer on fruit crops (Sanzani et al., 2013). For Alternaria, A. alternata and the A. arborescens species complex were detected, and the strains proved to be AOH/AME producers. Similar results were found for grape bunch rot during withering (Lorenzini and Zapparoli, 2014). In general, the presence of fun- 


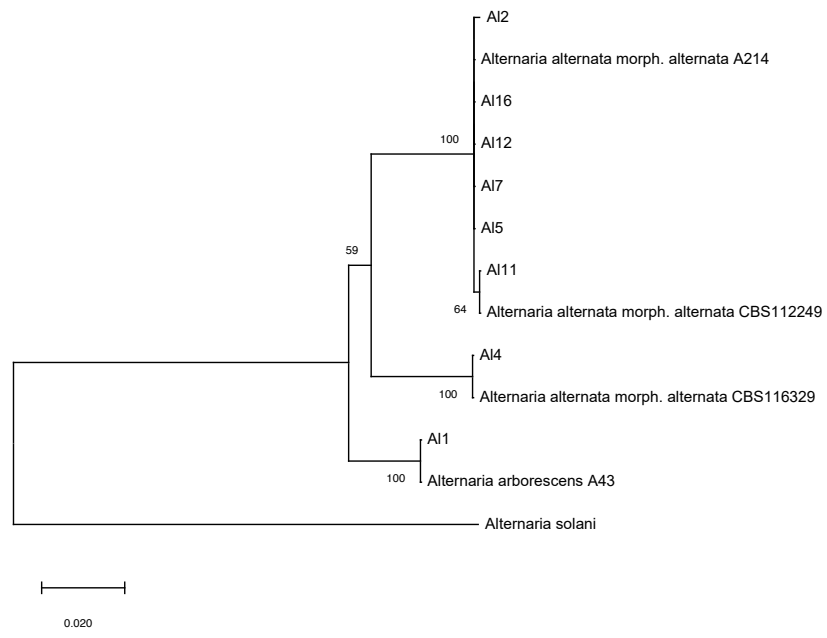

Figure 6. Phylogenetic tree for Alternaria strains based on a portion of the SCAR Marker OPA1-3. Numbers on nodes represent the Maximum Likelihood bootstrap percentages. Branch lengths are proportional to the numbers of nucleotide substitutions and can be measured using the bar scale (0.02).

gal pathogens was in line with other studies (Diaz et al., 2011; Oliveira et al., 2017; Ding et al., 2019).

Fungi, including Aspergillus, Penicillium, and Alternaria, can switch lifestyle between saprophytic and plant pathogenic forms. Mycotoxin production by these fungi may even affect their positions in ecological niches and their interactions with plants, animals, and the environment (Pfliegler et al., 2019), causing major effects on the severity of the diseases caused (Sanzani et al., 2012; Zaccaria et al., 2015; Wenderoth et al., 2019).

Harvested Lebanese table grapes were shown to harbour relevant fungal pathogens from spoilage and food safety perspectives, both as epiphytic agents and latent infections. Alternaria, Aspergillus, Penicillium, and Botrytis were the most commonly identified fungi. Furthermore, $\mathrm{SO}_{2}$ generating pads were found to be more effective for reducing epiphytic fungal populations during grape storage than for reducing latent infections, confirming the need of an effective field control of these infections. The mycotoxin producing genera Aspergillus, Penicillium, and Alternaria were characterized at species level. Strains of $A$. welwitschiae and $P$. expansum were also found, which are reported in grapes to be important producers of mycotoxins, the contents of which in food commodities is regulated by international legislation. As such, pre- and postharvest management should consider to control grape spoilage and to prevent mycotoxin production. Particularly, studies are recommended to assess conditions that favour fungal secretion of toxic secondary metabolites, and their fates during storage of table grapes.

\section{ACKNOWLEDGEMENT}

Jack Khalil was supported by a scholarship funded by CURE-XF, an EU-funded project coordinated by CIHEAM Bari (H2020-Marie Sklodowska-Curie Actions - Research and Innovation Staff Exchange. Reference number: 634353).

\section{LITERATURE CITED}

Abdelfattah A., Sanzani S.M., Wisniewski M., Berg G., Cacciola S.O., Schena L., 2019. Revealing cues for fungal interplay in the plant-air interface in vineyards. Frontiers in Plant Science 10: 922.

Aşkun T., Eltem R., Taşkın E., 2007. Comparison of RoseBengal chloramphenicol agar and Dichloran Glycerol Agar (DG18) for enumeration and isolation of moulds from raisins. Journal of Applied Biological Science 1(2): 71-75.

Barnett H.L., Hunter B.B., 1999. Illustrated Genera of Imperfect Fungi. 4th Edition, APS Press, St. Paul, MN, United States of America, $218 \mathrm{p}$.

Bokhari F., Aly M.M., 2009. Patulin production of Penicillium glabrum isolated from Coffea Arabica L. and the activities of some natural antifungal and antimycotoxin plants. Egyptian Journal of Microbiology 44: 47-59.

Chalak L., Touma S., Rahme S., Azzi R., Guiberteau F., Touma J.A., 2016. Assessment of the Lebanese grapevine germplasm reveals a substantial diversity and a high potential for selection. BIO Web of Conferences 7: 01020 .

Chiang K.S., Liu H.I., Bock C.H., 2017. A discussion on disease severity index values. Part I: warning on inherent errors and suggestions to maximise accuracy. Annals of Applied Biology 171(2): 139-154.

Covarelli L., Beccari G., Marini A., Tosi L., 2012. A review on the occurrence and control of ochratoxigenic fungal species and Ochratoxin A in dehydrated grapes, non-fortified dessert wines and dried vine fruit in the Mediterranean area. Food Control 26(2): 347-356.

de Souza Ferranti L., Fungaro M.H.P., Massi F.P., da Silva J.J., Penha R.E.S., ..., Iamanaka B.T., 2018. Diversity of Aspergillus section Nigri on the surface of Vitis labrusca and its hybrid grapes. International Journal of Food Microbiology 268: 53-60.

Díaz G.A., Yañez L., Latorre B.A., 2011. Low occurrence of patulin-producing strains of Penicillium in grapes and patulin degradation during winemaking in Chile. American Journal of Ecology and Viticulture 62: 542546. 
Ding S., Li N., Cao M., Huang Q., Chen G., ..., Li W., 2019. Diversity of epiphytic fungi on the surface of Kyoho grape berries during ripening process in summer and winter at Nanning region, Guangxi, China. Fungal Biology 123(4): 283-289.

Droby S., Lichter A., 2007. Post-Harvest Botrytis Infection: Etiology, Development and Management. In: Botrytis: Biology, Pathology and Control. (Y. Elad, B. Williamson, P. Tudzynski, N. Delen, eds.), Springer, Dordrecht, Germany, 349-367.

EC, 2006. Commission Regulation (EC) No 1881/2006 setting maximum levels for certain contaminants in foodstuffs. Official Journal of European Union 364: $5-24$.

EC, 2007. Commission regulation (EC) $\mathrm{N}^{\circ} 1126 / 2007$. 28 September 2007. Amending regulation (EC) $\mathrm{N}^{\circ}$ $1881 / 2006$ setting maximum levels for certain contaminants in foodstuffs as regards toxins in maize and maize products. Official Journal of European Union L 255: 14-17.

EFSA, 2011. Scientific opinion on the risks for animal and public health related to the presence of Alternaria toxins in feed and food. EFSA Journal 9(10): 2407.

FAOSTAT, 2019. Commodities by country. Available at http://www.fao.org/faostat/en/\#rankings/commoditiesbycountry. Accessed_April 25, 2020.

Fernandez-Trujillo J.P., Obando-Ulloa J.M., Baró R., Martinez J.A., 2012. Quality of two table grape guard cultivars treated with single or dual-phase release $\mathrm{SO}_{2}$ generators. Journal of Applied Botany and Food Quality $82(1): 1-8$.

Franck J., Latorre B.A., Torres R., Zoffoli J.P., 2005. The effect of preharvest fungicide and postharvest sulphur dioxide use on postharvest decay of table grapes caused by Penicillium expansum. Postharvest Biology and Technology 37(1): 20-30.

Frisvad J.C., 2018. A critical review of producers of small lactone mycotoxins: patulin, penicillic acid and moniliformin. World Mycotoxin Journal 11(1): 73-100.

Garganese F., Schena L., Siciliano I., Prigigallo M.I., Spadaro D., ... Sanzani S.M., 2016. Characterization of citrus-associated Alternaria species in Mediterranean areas. Plos One 11(9): e0163255.

Glass L.N., Donaldson G.C., 1995. Development of primer sets designed for use with the PCR to amplify conserved genes from filamentous ascomycetes. Applied Environmental Microbiology 61(4): 1323-1330.

Hong S.-B., Go S.-J., Shin H.D., Frisvad J.C., Samson R.A., 2005. Polyphasic taxonomy of Aspergillus fumigatus and related species. Mycologia 97(6): 13161329.
Hong S.B., Lee M., Kim D.H., Varga J., Frisvad J.C., ..., Samson R.A., 2013. Aspergillus luchuensis, an industrially important black Aspergillus in East Asia. PLoS One 8(5): e63769.

IARC, 1993. Some naturally occurring substances: food items and constituents, heterocyclic aromatic amines and mycotoxins. IARC Monographs on the Evaluation of the Carcinogenic Risk of Chemicals to Humans, 56. World Health Organization, Geneva, Switzerland, $599 \mathrm{p}$.

Kumar S., Stecher G., Li M., Knyaz C., Tamura K., 2018. MEGA X: molecular evolutionary genetics analysis across computing platforms. Molecular Biology and Evolution 35(6): 1547-1549.

Lachhab N., Sanzani S.M., Bahouaoui M.A., Boselli M., Ippolito A., 2016. Effect of some protein hydrolysates against gray mould of table and wine grapes. European Journal of Plant Pathology 144: 821-830.

Lebanese Chamber of Commerce, 2019. Agvisor (version 1.1) [mobile application software].

Lorenzini M., Zapparoli G., 2014. Characterization and pathogenicity of Alternaria spp. strains associated with grape bunch rot during post-harvest withering. International Journal of Food Microbiology 186: 1-5.

Mincuzzi A., Ippolito A., Montemurro C., Sanzani S.M., 2020. Characterization of Penicillium s.s. and Aspergillus sect. nigri causing postharvest rots of pomegranate fruit in Southern Italy. International Journal of Food Microbiology 314: 108389.

Murray M.G., Thompson W.F., 1980. Rapid isolation of high molecular weight plant DNA. Nucleic Acids Research 8(19): 4321-4326.

Oliveira M., Arenas M., Lage O., Cunha M., Amorim M.I., 2017. Epiphytic fungal community in Vitis vinifera of the Portuguese wine region. Letters in Applied Microbiology 66(1): 93-102.

Peever T.L., Su G., Carpenter-Boggs L., Timmer L.W., 2004. Molecular systematics of citrus-associated Alternaria species. Mycologia 96(1): 119-134.

Perrone G., Susca A., Cozzi G., Ehrlich K., Varga J., ..., Samson R.A., 2007. Biodiversity of Aspergillus species in some important agricultural products. Studies in Mycology 59: 53-66.

Perrone G., Gallo A., 2016. Aspergillus Species and Their Associated Mycotoxins. Methods in Molecular Biology 1542: 33-49.

Pfliegler W.P., Pócsi I., Győri Z., Pusztahelyi T., 2019. The Aspergilli and their mycotoxins: metabolic interactions with plants and the soil biota. Frontiers in Microbiology 10: 2921.

Rogers S.O., Bendich A.J., 1989. Extraction of DNA from plant tissues. In: Plant Molecular Biology Manual. 
(S.B. Gelvin, R.A. Schilperoort, D.P.S. Verma, eds.). Springer, Dordrecht, Germany, 73-83.

Rousseaux S., Diguta C.F., Radoï-Matei F., Alexandre H., Guilloux-Bénatier M., 2014. Non-Botrytis graperotting fungi responsible for earthy and moldy offflavors and mycotoxins. Food Microbiology 38: 104121.

Samson R.A., Noonim P., Meijer M., Houbraken J., Frisvad J.C., Varga J., 2007. Diagnostic tools to identify black Aspergilli. Studies in Mycology 59: 129-145.

Samson R.A., Visagie C.M., Houbraken J., Hong S.B., Hubka, V., ..., Frisvad J.C., 2014. Phylogeny, identification and nomenclature of the genus Aspergillus. Studies in Mycology 78: 141-173.

Sanzani S.M., Schena L., Nigro F., De Girolamo A., Ippolito A., 2009. Effect of quercetin and umbelliferone on the transcript level of Penicillium expansum genes involved in patulin biosynthesis. European Journal of Plant Pathology 125(2): 223-233.

Sanzani S.M., Schena L., De Cicco V., Ippolito A., 2012. Early detection of Botrytis cinerea latent infections as a tool to improve postharvest quality of table grapes. Postharvest Biology and Technology 68: 64-71.

Sanzani S.M., Montemurro C., Di Rienzo V., Solfrizzo M., Ippolito A., 2013. Genetic structure and natural variation associated with host of origin in Penicillium expansum strains causing blue mould. International Journal of Food Microbiology 165(2): 111-120.

Sanzani S.M., Reverberi M., Geisen R., 2016a. Mycotoxins in harvested fruits and vegetables: Insights in producing fungi, biological role, conducive conditions, and tools to manage postharvest contamination. Postharvest Biology and Technology 122: 95-105.

Sanzani S.M., Miazzi M.M., Di Rienzo V., Fanelli V., Gambacorta G., ..., Montemurro C., 2016b. A rapid assay to detect toxigenic Penicillium spp. contamination in wine and musts. Toxins 8(8): 235.

Sanzani S.M., Djenane F., Incerti O., Admane N., Mincuzzi A., Ippolito A., 2021. Mycotoxigenic fungi contaminating greenhouse-grown tomato fruit and their alternative control. European Journal of Plant Pathology 160: 287-300.

Schuchardt S., Ziemann C., Hansen T., 2014. Combined toxicokinetic and in vivo genotoxicity study on Alternaria toxins. EFSA supporting publication 2014: EN-679.

Simmons E.G., 2007. Alternaria. An identification manual. CBS biodiversity series 6. CBS Fungal Biodiversity Center, Utrecht, The Netherlands, 775 p.

Smilanick J.L, Harstell P.I., Henson D., Fouse D.C., Assemi M., Harris C.M., 1990. Inhibitory activity of Sulphur dioxide on the germination of spores of Botrytis cinerea. Phytopathology 80: 217-220.
Somma S., Perrone G., Logrieco A.F., 2012. Diversity of black Aspergilli and mycotoxin risks in grape, wine and dried vine fruits. Phytopathologia Mediterranea 51: 131-147.

Stocco A.F., Diaz M.E., Rodríguez Romera M.C., Mercado L.A., Rivero M.L., Ponsone M.L., 2019. Biocontrol of postharvest Alternaria decay in table grapes from Mendoza province. Biological Control 134: 114-122.

Storari M., Bigler, L., Gessler, C., Broggini, G.A.L., 2012. Assessment of the Ochratoxin A production ability of Aspergillus tubingensis. Food Additive and Contaminants: Part A 29(9): 1450-1454.

Susca A., Proctor R.H., Butchko R.A., Haidukowski M., Stea G., ..., Moretti A., 2014. Variation in the fumonisin biosynthetic gene cluster in fumonisin-producing and nonproducing black aspergilli. Fungal Genetics and Biology 73: 39-52.

Susca A., Proctor R.H., Morelli M., Haidukowski M., Gallo A., ..., Moretti A., 2016. Variation in fumonisin and ochratoxin production associated with differences in biosynthetic gene content in Aspergillus niger and $A$. welwitschiae isolates from multiple crop and geographic origins. Frontiers in Microbiology 7: 1412.

Tamura K., Nei M., 1993. Estimation of the number of nucleotide substitutions in the control region of mitochondrial DNA in humans and chimpanzees. Molecular Biology and Evolution 10(3): 512-526.

Visagie C.M., Houbraken J., Frisvad J.C., Hong S.B., Klaassen C.H.W., ..., Samson R.A., 2014. Identification and nomenclature of the genus Penicillium. Studies in Mycology 78: 343-371.

Wenderoth M., Garganese F., Schmidt-Heydt M., Soukup S.T., Ippolito A., ..., Fischer R., 2019. Alternariol as virulence and colonization factor of Alternaria alternata during plant infection. Molecular Microbiology 112(1): 131-146.

Woudenberg J.H.C., Groenewald J.Z., Binder M., Crous P.W., 2013. Alternaria redefined. Studies in Mycology 75(1): 171-212.

Woudenberg J.H.C., Seidl M.F., Groenewald J.Z., De Vries M., Stielow J.B., ..., Crous P.W., 2015. Alternaria section Alternaria: Species, formae speciales or pathotypes? Studies in Mycology 82: 1-21.

Youssef K., Junior O.J.C., Mühlbeier D.T., Roberto S.R., 2020. Sulphur dioxide pads can reduce gray mold while maintaining the quality of Clamshell-packaged 'BRS Nubia' seeded table grapes grown under protected cultivation. Horticulturae 6(20): 2-9.

Zaccaria M., Ludovici M., Sanzani S.M., Ippolito A., Cigliano R.A., ..., Reverberi M., 2015. Menadione-induced oxidative stress re-shapes the oxylipin profile of Aspergillus flavus and its lifestyle. Toxins 7(10): 4315-4329. 